\title{
Pregnant or positive: Adolescent childbearing and HIV risk in South Africa
}

\author{
Naomi Rutenberg \\ Population Council \\ Carol E. Kaufman \\ Kate Macintyre \\ Lisanne Brown \\ Ali Mehyrar Karim
}

Follow this and additional works at: https://knowledgecommons.popcouncil.org/departments_sbsr-pgy

Part of the Demography, Population, and Ecology Commons, Family, Life Course, and Society Commons, International Public Health Commons, and the Maternal and Child Health Commons How does access to this work benefit you? Let us know!

\section{Recommended Citation}

Rutenberg, Naomi, Carol E. Kaufman, Kate Macintyre, Lisanne Brown, and Ali Mehyrar Karim. 2002. "Pregnant or positive: Adolescent childbearing and HIV risk in South Africa," Policy Research Division Working Paper no. 162. New York: Population Council. Version of record: https://www.jstor.org/stable/ 3776051 
Pregnant or Positive:

$>$

-

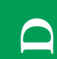
Adolescent Childbearing and HIV Risk in South Africa

Naomi Rutenberg

Carol E. Kaufman

Kate Macintyre

$\approx$

Lisanne Brown

$\varangle$

Ali Karim

[I]

$\infty$

2002 No. 162

뚀

$\simeq$

$\gg$

u

$\mapsto$

$\mapsto$

0

ค

$5 \bigcirc \underset{1952-2002}{\mathrm{Y} E A R S}$

1 Population Council 


\title{
Pregnant or Positive: Adolescent Childbearing and HIV Risk in South Africa
}

\author{
Naomi Rutenberg \\ Carol E. Kaufman \\ Kate Macintyre \\ Lisanne Brown \\ Ali Karim
}

Naomi Rutenberg is Senior Program Associate, Population Council, 4301 Connecticut Avenue NW, Suite 280, Washington, DC 20008. E-mail: nrutenberg@pcdc.org. Carol E. Kaufman is Project Director, University of Colorado Health Sciences Center, Denver, CO. Kate Macintyre is Assistant Professor, Lisanne Brown is Research Assistant Professor, and Ali Karim is Research Assistant, Department of International Health and Development, Tulane University, New Orleans. 


\begin{abstract}
In communities where early age of childbearing is common and HIV prevalence is high, adolescent boys and girls may place themselves at risk of HIV to realize their childbearing preferences. In this paper, we analyze survey data from KwaZulu-Natal province that explores whether an association exists between pregnancy preferences and behavioral and perceptual measures of HIV risk among adolescents in South Africa. Our analysis is based on data from 1,426 sexually active respondents aged 14-22 who participated in wave 1 of the "Transitions to Adulthood in the Context of AIDS in South Africa" study. We use logistic regression to model the probability of reporting that pregnancy would be a problem, using measures of HIV risk together with controls for individual and community measures that are also likely to affect pregnancy preferences. We find that educational and employment opportunities affect fertility preferences but also that the HIV pandemic, specifically adults' perception of HIV risk for the young in the community and peer opinions about HIV risk, affect fertility preferences. Some significant differences by sex emerge concerning the influence of the perceptions of HIV risk. The analysis suggests that although individual and structural factors remain important, for some adolescents - and for girls more than for boys - the danger of HIV infection is becoming part of their calculus of the desirability of pregnancy. For both boys and girls, the unprotected sex required for conception puts them at danger of HIV transmission. For girls, the environment of risk may be particularly influential because the double threat of pregnancy and HIV infection carries an additional risk of HIV transmission to the infant, as well as the possibility of learning one's serostatus at an antenatal clinic during pregnancy.
\end{abstract}

This material may not be reproduced without written permission from the authors. For a list of Policy Research Division Working Papers, including those available for downloading in PDF format, see www.popcouncil.org/publications/wp/prd/rdwplist.html. 
Patterns of adolescent fertility and HIV infection are not independent of one another. Conditions and behaviors producing sustained high levels of teenage pregnancy are likely also to bear upon adolescents' likelihood of acquiring HIV. This circumstance is borne out particularly in sub-Saharan Africa, where some of the highest levels of adolescent fertility occur in countries where HIV infection is most pervasive among the young. For example, in Botswana, Zambia, and Zimbabwe, countries in which more than 40 percent of 20-24-year-olds have given birth by age 20, more than one-fourth of 15-19-year-old girls attending antenatal clinics in the capital cities are infected with HIV (Singh 1998; U.S. Census Bureau 1999). Although these statistics suggest a relationship between two daunting demographic trends, in the social science and public health literature these phenomena are commonly considered as distinct processes. Studies focus on the determinants of either HIV transmission or early pregnancy; few investigations consider how (perceived) risk of HIV transmission might influence the desirability of pregnancy or vice versa. In other words, in the context of the AIDS pandemic, different valuations of risk are likely to influence preferences for childbearing; yet, we know little about how reproductive preferences are shaped by young people's awareness of the risk of HIV infection.

In a recent article, Preston-Whyte refers to the "fertility conundrum," the conflict between safer sex practices (condom use or abstinence) and the desire to become pregnant (Preston-Whyte 1999). She argues that although this dilemma affects women in many settings, African women are particularly vulnerable because of the paramount importance their cultures place on fertility. Furthermore, adolescents, because of their rapid physiological and developmental changes, inexperience, and sense of invulnerability, may experience even greater conflict than adults in considering the costs and benefits of pregnancy and risk reduction. This stress may be exacerbated by intergenerational tensions related to partner choice, sex, and condom or contraceptive use (Gage 1998). In communities where early age of childbearing is common and HIV prevalence is high, are adolescents who wish to delay childbearing doing so because of the risk environment?

We address this question by considering the case of South Africa. South Africa has high levels of teenage childbearing: About 30 percent of 20-24-year-olds have given 
birth by the age of 20 (Central Statistical Service 1997). At the same time, the country is experiencing extremely high levels of HIV prevalence coupled with one of the fastestgrowing rates of infection in the world. The story is especially bleak among the young: In 1994, 7 percent of 15-19-year-olds were HIV-positive; by 1998, that number was 21 percent (Whiteside 1999). Although recent figures show a decline in prevalence for this age group (16 percent in 2000), levels are still high, and for 20-24-year-olds it has increased to 28 percent (AIDS Analysis Africa 2001). Using data collected among young people in 1999 in KwaZulu-Natal province, this paper considers the relationship between preferences for childbearing among adolescents and the extent to which HIV is perceived as a risk in their lives and environment.

\section{REPRODUCTIVE DECISIONMAKING AND HIV IN AFRICA}

Numerous studies have documented lower fertility rates among populations of HIV-infected women in sub-Saharan Africa (see Ryder et al. 1991; Allen et al. 1993; Kigadye et al. 1993; Sewankambo et al. 1994; Carpenter et al. 1997; Gray et al. 1998; Desgrées du Loû et al. 1999; Ross et al. 1999; and Glynn et al. 2000). Many of these studies focus on the biological mechanisms influencing reproduction. Direct biological effects of HIV infection such as secondary amenorrhea, fetal wastage, and accelerated disease progression associated with pregnancy and/or coinfection with other sexually transmitted infections may reduce fertility among HIV-infected women. Increasingly, however, research has also revealed behavioral links to lowered fertility. For example, men and women may avoid pregnancy so as not to have a child that might be orphaned (Rutenberg et al. 2000). Death, unemployment, or divorce within a household that comes in the wake of HIV infection may have important economic or psychological consequences that affect the desirability of a pregnancy; or, simply, sexual intercourse may not occur as often, as a result of divorce, illness, or death of a partner (Gregson et al. 1997; Macintyre et al. 2001).

Such behavioral links to lowered fertility have been theorized, but empirical evidence to support fertility limitation among HIV-positive women is scarce. For example, studies conducted in Rwanda and Zambia revealed a widely held belief that all children born to HIV-positive women are infected with AIDS from their mothers and die and that 
if diagnosed as HIV-positive, a woman should not become pregnant (Allen et al. 1993; Rutenberg et al. 2000). To date, no studies have isolated deliberate fertility control among women living with HIV in sub-Saharan Africa as a behavioral cause of lowered fertility. For example, interventions with HIV-positive women in Africa have not been found to motivate a significant change in reproductive outcomes. Couples appeared to be cognizant of the risk of HIV - particularly, for their children — and have reported changes in contraceptive behavior, yet fertility levels have not been greatly affected (Temmerman et al. 1990; Kamenga et al. 1991; Allen et al. 1992 and 1993; Aka-Dago-Akribi et al. 1999).

In the absence of the signs and symptoms of AIDS at the individual level, awareness of the HIV epidemic at the community level has had little impact on decisions about whether and when to have children (Setel 1995). In one study in Zambia, when asked whether the risk of HIV has changed the way people in their community think about the number of children they would like to have or when to have them, respondents were perplexed about how HIV would affect these decisions unless a person knew that he or she was infected (Rutenberg et al. 2000). This separation between the silent HIV infection and fertility decisions was also observed in Côte d'Ivoire, another country with high HIV-infection prevalence, where one study found no fertility differences between HIVpositive women who were unaware of their status and HIV-negative women (Desgrées du Loû et al. 1999).

A number of factors may contribute to this lack of deliberate fertility limitation among HIV-infected and -affected women. Instead of — or because of a lack of-HIV testing, for example, pregnancy has been used to demonstrate the absence of infection and continuing good health. If a woman knows or suspects that she is infected with HIV, a pregnancy can affirm her own health or at least her capacity to bear a healthy child. Ankrah (1991) relates that an upsurge in pregnancies in Kampala in 1989-90 was explained locally as reflecting the belief that if a newborn child survived for one year, the mother was free of HIV. Women also frequently assert that the underlying motivation for demonstrating good health — and hiding one's HIV status—is the fear of abandonment and rejection. Whereas often this fear is about abandonment by a spouse or family (Family Health International/AIDSCAP 1996; Maman et al. 1999), rejection by communities is also feared. For example, in Côte d'Ivoire, couples in which only one partner 
has HIV often choose to have more children to avoid the risk of rejection by the community (Aka-Dago-Akribi et al. 1999). ${ }^{1}$ Finally, regardless of their own desired reproductive response to HIV infection, many women cannot negotiate with their partners about reproductive decisions and contraceptive use (Ryder et al. 1991; Keogh et al. 1994; King et al. 1995; Meursing and Sibindi 1995). Simply put, the decision whether or not to have another child is made by someone else.

Findings from studies linking HIV and fertility generally suggest that fertility desires take priority over disease prevention. The literature still contains several important gaps, however. First, research has tended to focus on women or couples of confirmed HIV status. Second, none of the studies focuses on the experience of the young, although pregnancy rates are high for this group in many sub-Saharan African countries and among populations with high rates of HIV seropositivity. Moreover, these studies reveal little about how reproductive preferences put women and men at risk of HIV infection or about how those risks might differ by sex or age.

The questions raised by the information currently available are particularly critical in South Africa in light of its high levels of adolescent childbearing and HIV infection. In order to understand how fertility and HIV risk might be interrelated, an understanding of the context and culture of sexual activity among adolescents in South Africa is important.

\section{Context and Culture of Teenage Sexual ACtivity IN SOUTH AFRICA}

The pattern of early childbearing in South Africa has persisted over many decades (Preston-Whyte 1990); indeed, Preston-Whyte and Zondi (1992) and Caldwell and Caldwell (1993) have suggested that this pattern has produced, if not an expectation, at least an acceptance of teenage childbearing. Recent evidence presents uneven support for this idea. In a study of young people aged 16 to 20 from three major metropolitan areas in the country, Richter (1996) reports that the vast majority wish to delay childbearing at least until the completion of their studies or until they have the means to provide for a child. Focus-group participants in the township of Khutsong indicated that loss of educational opportunities and economic hardship were reasons that as teenagers 
they avoided pregnancy rather than welcoming it (MacPhail and Campbell 2001). However, about 12 percent of the 16-19-year-old girls in Richter's study indicated they wanted to have a child in the next year or two, and of those, the majority wanted to do so in order to prove their fertility. In another study in Northern province, adolescent girls participating in focus groups and in-depth interviews stated that they wished to prove fertility, primarily to cement a relationship with a boyfriend or because they feared that using a contraceptive prior to having a child would result in infertility (Wood et al. 1998).

Although the majority of adolescents may not wish to become parents in the near future, they are nevertheless subject to considerable peer pressure to have a boyfriend or girlfriend and, for boys especially, to have many partners. Having a boyfriend or girlfriend is synonymous with having sex for most African young people. Sexual activity with a partner confers the status of a relationship, and for girls may bring benefits in the form of gifts or of financial support. For boys, having many girlfriends can be an affirmation of their manhood (Varga and Makubalo 1996; Varga 1997). As a result of these attitudes and pressures, sexual activity is common among South African adolescents (Richter 1996; Rutenberg et al. 2001).

The high prevalence rates of HIV infection among the young indicate that much of this sexual activity is unprotected. Recent figures from knowledge and attitude studies show high levels of awareness of HIV/AIDS for the younger age groups, and uneven but still relatively high awareness of means of HIV prevention in both urban and rural settings (Richter 1996; Jackson and Harrison 1999). These studies also show that whereas knowledge of HIV/AIDS is high, ignorance about reproduction and fertility remains pervasive.

Education and increased reproductive knowledge are not sufficient for preventing early sexual activity, teen pregnancy, or HIV transmission. For example, in focus groups, girls expressed little patience with ignorance as an explanation for teen pregnancy, arguing that sex education is now part of school, and that everyone who goes to school should be well aware of the dangers of "having boyfriends" (Wood and Jewkes 1997; Kaufman et al. 2000). Adolescents, girls in particular, also need the skills for communicating and negotiating with partners. The research findings in these areas are discouraging: Communication between partners is low or nonexistent (Gready et al. 1997), and girls usually have little power or say in relationships, making negotiation, as Varga 
and Makubalo (1996) term it, "non-negotiation." Violence and coercion are often a part of adolescent relationships in many settings. What may be unique to South Africa is the level at which this is true. South Africa has one of the highest levels of reported rape in the world, and violence against women is commonplace (Jewkes et al. 1999; PrestonWhyte 1999). That this type of violence, and the violence children experience and witness around them as they grow (Ramphele 1997), are reproduced within early sexual relationships is not surprising.

A number of studies report that women often feel they have little choice but to have sex with their partners, and indeed that many first experiences may have been coerced (Varga 1997; Wood and Jewkes 1997; Jewkes et al. 1999). Wood and her colleagues note that coercion is so commonplace in adolescent relationships that many do not recognize it as violence or as aberrant. Violence related to condom use is frequently cited in the literature. The desire to use a condom conveys mistrust of a partner or a presumption of infidelity or uncleanness (Lurie et al. 1997; Varga 1997). Extreme gender power differentials make communication about condoms difficult, and suggesting use can result in physical abuse or rape (Varga and Makabalo 1996; Wood and Jewkes 1997; Wood et al. 1998; MacPhail and Campbell 2001). Physical abuse is not the only potential outcome of broaching the topic of condom use within a relationship. Respondents of both sexes report fear of desertion if they suggest condom use to their partners, a consequence that can have severe economic implications, especially for women. At the same time, many women as well as men report a distaste for condoms, and many would be offended if their (main) partner suggested using one (Varga 1999).

Perceived risk of HIV infection-for oneself or others-has not been assessed systematically in South Africa. Young people's statements in group discussions or interviews reveal, however, that although awareness of HIV is high, they prefer to see themselves as being at low risk of infection (CASE 1995; NPPHCN 1995; Varga 1997). LeClerc-Madlala (1997) suggests that this attitude of denial is underpinned by a fear of death and of dying alone; the theme of self-preservation in the form of denial is common in the literature (see, for example, Ulin 1992 and Lear 1995).

Not all information about South African adolescents' sexual practices and perceptions is discouraging. Although it is speculative, recent evidence suggests that per- 
ceptions and consequent actions are changing. Varga (1999) and Preston-Whyte (1994 and 1999) explore how condom use can be "situational" (men, for example, may be willing to use a condom with prostitutes, but not with their wives) and suggest that young men and women are undergoing a shift in their thinking about what kinds of situations require condoms. Both show an increased openness to discussing condom use and to considering, at least in the abstract, that their consistent use might be appropriate. MacPhail and Campbell (2001: 1625) found among their focus-group respondents "areas of debate and difference in the views [about condom use]" that could provide a foundation for peer-education programs that lead to the possibility of behavioral change. From research among adolescents at six sentinel sites in South Africa, Kelly (2000) reports a higher level of condom use than previously published in roughly comparable studies. A comparison of condom use across age groups as reported in the 1998 South African Demographic and Health Survey (SADOH and MI 1999) provides support for these observations; 20 percent of 15-19-year-olds and 14 percent of 20-24-year-olds indicated they had used a condom the last time they had sexual intercourse, compared with 7 percent or less of any other age group. As condom use appears to be increasing among the young, their cognizance of risk also may be shifting.

Adolescents are under tremendous pressure to have sex at early ages. Having a child is a common experience and, for some, an intended experience. Conceiving a baby in the context of high prevalence of AIDS, however, is commensurate with sexual risktaking. Are young men and women who wish to delay pregnancy influenced by the AIDS pandemic? Specifically, do perceptions of the environment of HIV risk affect their own perception of the risk of HIV transmission and thus influence their preferences for childbearing?

\section{DATA AND METHODS}

To examine the relationship between fertility intentions and the perception of the risk of HIV transmission, we use data collected in 1999 from the first round of a longitudinal study of young adults in KwaZulu-Natal province entitled "Transitions to Adulthood in the Context of AIDS in South Africa." This study is part of a larger research project that seeks to fill some of the gaps in our knowledge about adolescent sexual 
behavior and reproductive health outcomes and about the interaction of educationincluding life-skills education - and work experience with reproductive events and sexual health.

KwaZulu-Natal (KZN) province lies on the east coast of South Africa along the Indian Ocean. With a population of 8.4 million, KZN is South Africa's largest province, containing one-fifth of the country's population. The population of the province is about 45 percent urban and includes Durban, the largest port and third-largest city in the country. About 25 percent of the country's African population resides in the province. Africans, primarily Zulu-speaking, make up about 76 percent of the KZN population, Indians are 14 percent, whites are 7 percent, and 3 percent are colored (of mixed ancestry).

KZN has the highest level of HIV infection in the country; among antenatal clinic attendees HIV prevalence was an estimated 36 percent in 2000 (AIDS Analysis Africa 2001). The high prevalence and rapid rise in its level have been attributed to widespread migrant labor in the province and its association with multiple partners; lack of condom use (mainly because of the method's association with distrust between partners and with a lack of cleanliness); the high value men place on multiple partnerships; high levels of poverty; and poor health-care services (Whiteside 1999).

For this study, two districts-Durban Metro and Mtunzini-were purposively selected as the target areas for study in order to encompass urban, transitional, and rural regions within the province. The study used a modified multistage cluster sample. The first stage required random selection of 120 enumeration areas (EAs) from a sampling frame of all EAs in the two districts. In the second stage, enumeration areas were divided by field staff into segments of approximately equal size (based on an estimate for the average number of adolescents we could expect to find per household). ${ }^{2}$ One segment was selected randomly, and interviewers endeavored, within as many as four visits, to interview in every household all young people between the ages of 14 and 22 reported to be living in those households.

Information on household composition, living conditions, and selected economic data was collected through an interview with the household head or with the adolescent identified for the individual interview. Data from individual adolescents were collected through a structured questionnaire, which took between 50 minutes and an hour and a 
half to administer. Respondents were asked to provide detailed education and work histories as well as information on sexual activity, reproductive decisions, contraceptive use, and pregnancies. Questions were also asked about HIV/AIDS knowledge, perception of HIV risk and stigma, condom use and accessibility, and alcohol and drug use. The datacollection teams were composed of male and female whites, Asians, and Africans, and all interviews were conducted by interviewers of the same race and sex as the respondents.

The first wave of data collection included structured interviews in 118 of the 120 selected segments with 1,974 households that had adolescent members between the ages of 14 and 22. In these households, interviewers identified 3,770 adolescents and completed individual interviews with 3,052 respondents. Of these, approximately half the adolescents reported that they had ever had sex. The analysis is restricted to those who ever had sex because the issue of a pregnancy in the near future had greater significance for this group than for others. ${ }^{3}$ Cases that came from enumeration areas with fewer than ten respondents were excluded to ensure that the index case would not bias the variables based on aggregated community data (described below) and to ensure that those estimates were stable. The analysis was begun with 1,426 respondents, and an additional 111 cases were dropped because of missing values for the dependent or independent variables. This data set includes the African, white, and Asian population groups ${ }^{4}$ and the analysis is based on weighted data to control for clustering and nonresponse.

Community characteristics were assessed in an independent data-collection effort in 110 of the 118 sampled enumeration areas. ${ }^{5}$ The perception of HIV risk and attitudes toward people living with AIDS were assessed using a street-interview module, in which the field-workers conducted interviews with people living in the community. Interviewers recruited respondents at several central locations, such as in shopping centers, bus stops, or along busy streets. "Community" was defined by the administrative boundaries of the enumeration area. For the street interviews, field-workers described these boundaries to respondents to establish their eligibility to participate and to define for them the area to which questions referred. Field supervisors instructed interviewers to talk with 40 respondents living in the EA who were evenly divided by sex and by age group: 14 to 30 years old and 31 and older. This number and balance were achieved in most EAs. In an analysis of the internal validity of the data gathered in the street-inter- 
view module, Brown et al. (2001) found that responses to comparable questions on safety, crime, and perceptions of HIV risk in the module were similar to those of the interviewed adolescents. In sum, after all exclusions for data or methodological reasons, data from 98 enumeration areas were used for the analysis of boys' responses and from 94 enumeration areas for that of girls' responses.

The measure of the desirability of pregnancy is based on the responses to the following question:

In the next few weeks, if you discovered that you were pregnant, would that be a big problem, a small problem, or no problem at all? (For boys the question was modified to begin: If you discovered that your partner was pregnant ....)

Responses were coded so that a categorical measure was obtained of whether the individual boy or girl thought that pregnancy would be a big problem, a small problem, or no problem.

The analysis includes three measures of the individual respondent's risk environment. The first measure is whether the respondent knows someone who died of AIDS, based on the question: Do you personally know anyone who has died, or who you think has died, of AIDS?

Macintyre et al. (2001) found that personal experience of AIDS predicted behavioral change among men in a three-country study in eastern and southern Africa. One implication is that behavioral change is partly determined by the high level of mortality experienced by African communities. A second implication is that higher levels of disclosure, or lower levels of denial of AIDS as a cause of death, may help individuals change their behavior. Two environmental measures of risk are included in the present analysis. The first is the proportion of respondents in an enumeration area who believe that their friends are at risk of HIV infection. A strong association within peer groups exists between various sexual behaviors (for example, the proportion who are sexually active, the rate of partner change, and condom use) (Kirby 2001). Our variable "proportion who perceive that friends are at risk of HIV infection" measures the extent to which the peergroup behaviors are viewed as risky. The second measure of environmental risk is based on data from the community interview about whether adult respondents think that young 
people in their community are at risk of acquiring HIV. The response to this variable is measured on a three-point scale. We calculated the mean response for each enumeration area. A response of one indicates that every adult respondent in a cluster reported that adolescents are at low risk for acquiring HIV, and a response of three indicated that everyone reported high risk. We include this measure as a proxy for an "objective" assessment of the risk environment measured at the community level. ${ }^{6}$

Additionally, we include in the analysis a number of variables that measure socioeconomic context and access to emotional and material resources that might influence an adolescent's calculation of the costs and benefits of pregnancy. These variables were selected on the basis of previous findings in the literature and on exploratory analysis that had emphasized or suggested their importance for understanding pregnancy preferences. Certain behavioral measures are excluded, such as condom use, that are endogenous to fertility preferences (Hermalin 1983).

Our independent variables based on data from individuals include age (in three categories: $14-15,16-19$, and 20-22) and race, following the statistical classification used in South Africa - namely, Africans, white, and Asian. Because the number of Asian and white respondents is small, these two categories are combined for the regression analysis. A third control variable is whether the respondent is currently involved in a stable relationship - either with a spouse (1 percent of respondents were married) or with a steady boyfriend or girlfriend. About 55 percent of respondents with a steady boy or girlfriend and 45 percent of single respondents reported having had sex in the previous four weeks. Therefore, this relationship variable is not a measure of sexual activity, but is included to capture whether the respondent was in a relationship likely to be socially sanctioned and lasting, and whether it might offer support for a baby.

Also included were three controls derived from the household-level data that were found to be significant predictors of condom use-and possibly of fertility control-in this population in an unpublished analysis. The first is a wealth index created using item analysis. An initial pool of 11 items that are thought to measure household wealth was entered into the item analysis. Cronbach's alpha identifies an internally reliable index, that is, a set of items that are highly intercorrelated and are assumed to measure the same construct, in this case household wealth. Six items were retained for 
the final index (roof type, wall type, toilet type, water source, electricity supply, and telephone ownership), with a Cronbach's alpha of 0.87. A second variable captures whether the household has no parent living in the house, both parents, or one. This variable is considered a measure of the level of parental supervision of adolescents and a measure of household cohesion. The final control measures the stability of the household in terms of the number of "shocks" the household has experienced in the past 12 months; shocks include recent unemployment, a divorce, illness, or death.

Finally, the analysis draws upon recent work on community context and risktaking behavior among young people in the United States indicating that conditions in communities, such as level of unemployment or crime, influence the choices young adults make, including their childbearing preferences (Duncan and Raudenbush 1999; Kirby 2001). We selected community-level factors to capture the dynamics of the environments in which adolescents live and participate, and we constructed community variables to reflect opportunities for education, that is, the proportion of adolescents enrolled in school at any level, and for employment, specifically, the proportion of young people who are currently working. These variables were constructed by aggregating observations concerning individuals to the enumeration-area level.

Logit regression techniques are used to model the relationship between fertility preferences and risk of acquiring HIV, with adjustments to the standard errors to accommodate the cluster design of the study. Because of the expected differences in experiences by sex, we estimate each model separately for boys and for girls.

\section{RESULTS}

In response to the question of whether pregnancy in the next few weeks would be a big, small, or no problem - the dependent variable in the analysis - the majority of boys and girls, about 74 percent, said that a pregnancy in the next few weeks would be a big problem (not shown). Girls were more likely than boys to give this response (78 percent compared with 70 percent), but the difference was not statistically significant.

Table 1 shows the distribution of the independent variables for the 1,426 sexually active adolescents in our sample. Fifty-two percent of our respondents are female, 5 percent are 14 or 15 years old, slightly more than half are between 16 and 19 years old, 
Table 1 Percentage distribution of respondents by selected variables, according to sex, KwaZulu-Natal province, South Africa, 1999

\begin{tabular}{|c|c|c|c|}
\hline Variable & Male & Female & Total \\
\hline \multicolumn{4}{|l|}{$\overline{\text { Age group }}$} \\
\hline $14-15$ & 5.9 & 4.4 & 5.1 \\
\hline $16-19$ & 56.6 & 51.6 & 54.0 \\
\hline $20-22$ & 37.5 & 44.0 & 40.9 \\
\hline \multicolumn{4}{|l|}{ Race } \\
\hline African & 85.0 & 91.7 & 88.5 \\
\hline Other & 15.0 & 8.3 & 11.5 \\
\hline \multicolumn{4}{|l|}{ Relationship status } \\
\hline Steady relationship & 51.5 & 37.2 & 44.1 \\
\hline Single & 48.5 & 62.8 & 55.9 \\
\hline \multicolumn{4}{|c|}{ Household wealth index (number of items of basic infrastructure) } \\
\hline $1-2$ & 2.4 & 2.1 & 2.3 \\
\hline $3-4$ & 37.4 & 34.4 & 31.0 \\
\hline $5-6$ & 70.1 & 63.5 & 66.7 \\
\hline \multicolumn{4}{|c|}{ Parents living in household } \\
\hline Both & 43.4 & 33.2 & 38.1 \\
\hline One & 36.0 & 38.3 & 37.2 \\
\hline Neither & 20.6 & 28.5 & 24.7 \\
\hline \multicolumn{4}{|c|}{ Number of household shocks } \\
\hline 0 & 52.6 & 55.4 & 54.0 \\
\hline 1 & 24.6 & 24.3 & 24.5 \\
\hline $2+$ & 22.8 & 20.3 & 21.5 \\
\hline \multicolumn{4}{|c|}{ 14-22-year-olds in the neighborhood enrolled in school } \\
\hline$<51$ percent & 1.9 & 2.2 & 2.0 \\
\hline $51-75$ percent & 59.0 & 60.3 & 59.6 \\
\hline $76-100$ percent & 39.2 & 37.6 & 38.3 \\
\hline \multicolumn{4}{|c|}{ 14-22-year-olds in the neighborhood worked in last 12 months } \\
\hline$<51$ percent & 17.3 & 17.5 & 17.4 \\
\hline $51-75$ percent & 51.3 & 47.0 & 49.1 \\
\hline $76-100$ percent & 31.4 & 35.6 & 33.5 \\
\hline \multicolumn{4}{|c|}{ Knows someone who died of AIDS } \\
\hline No & 68.8 & 61.3 & 64.9 \\
\hline Yes & 31.2 & 38.7 & 35.1 \\
\hline \multicolumn{4}{|c|}{$\begin{array}{l}\text { Perception of friends' risk of acquiring HIV } \\
\text { (mean percent for community) }\end{array}$} \\
\hline$<10$ & 9.2 & 7.2 & 8.2 \\
\hline $10-35$ & 79.4 & 77.6 & 78.5 \\
\hline$>35$ & 11.4 & 15.2 & 13.4 \\
\hline \multicolumn{4}{|c|}{$\begin{array}{l}\text { Adults who think that young people are at risk of acquiring HIV } \\
\text { (mean score for community; continuous } 1=\text { low to } 3=\text { high) }\end{array}$} \\
\hline $1.00-1.76$ & 29.6 & 26.8 & 27.8 \\
\hline $1.77-2.50$ & 39.2 & 38.2 & 38.2 \\
\hline $2.51-3.00$ & 31.2 & 35.0 & 32.8 \\
\hline$(\mathrm{N})$ & $(688)$ & (738) & $(1,426)$ \\
\hline
\end{tabular}


and 41 percent are 20 to 22 years old. Nearly 90 percent of the subsample are black South Africans. A majority (56 percent) of respondents are single and most of those who are in a relationship reported their partner to be their boyfriend or girlfriend. Boys are more likely than girls to be in a relationship. One-third of the adolescents surveyed live in households that lack two or more items of basic infrastructure. A minority of adolescents, 38 percent, live with both parents, and one-fourth live with neither parent. Boys were more likely than girls to live with both parents and in better-off households. Nearly half of the adolescents had experienced a significant shock in their household, such as recent unemployment, a divorce, illness, or death, in the previous year.

The adolescents in the study live in communities having substantial levels of school enrollment and work opportunities. Nearly all (98 percent) adolescents live in communities where more than 50 percent of the young aged 14-22 are enrolled in school. More than one-third live in environments where between 75 and 100 percent of adolescents aged 14-22 are currently attending school. Eighty-three percent live in communities where more than 50 percent of the young have earned money for work within the last 12 months. These results suggest that despite the many obstacles that these South African adolescents face in trying to stay in school and in finding work, their immediate environment offers opportunities and places a high value on education and employment.

Only about one-third of the adolescents surveyed know someone who has died of AIDS. Girls were more likely than boys to report knowing someone who died in this way. More than 75 percent of the adolescents live in communities where a moderate proportion, 10-35 percent, say their friends are at risk of acquiring HIV. Fewer than 10 percent live in communities where few adolescents thought their friends were at risk, and about 13 percent of young respondents live in communities where more than onethird of adolescents think their friends are at risk. Not surprisingly, adults perceive more risk for young people in their communities than do the adolescents themselves, who are inclined to underestimate their vulnerability. Just over one-fourth of adolescents surveyed live in communities where a relatively small proportion of adults think the young are at risk of acquiring HIV, almost 40 percent live in communities where around half of adults perceive this risk, and one-third live in communities where most adults believe 
that the young are at risk of acquiring HIV. Girls were slightly more likely than boys to live in communities with a greater perception of HIV risk.

The results of the logistic regressions that examine the relationships between the perception of pregnancy as a problem and HIV risk are shown in Table 2. The dependent variable, perception of a pregnancy as a problem, was coded as one if a pregnancy would be a big problem and as zero otherwise. Race, age, whether currently in school, currently in a sexual relationship, and the three measures of household well-being (wealth, parents in the home, and the number of shocks in the last year) are included as control or mediating variables.

Among sexually active boys, age, race, wealth, and the proportion of adults who think that young people in their community are at risk of acquiring HIV are significant predictors that a pregnancy in the near future would be a big problem for them and that they might seek to delay pregnancy. Congruent with expectation, compared with younger boys, those in the older age group (20-22) are much less likely to state that a pregnancy would be a problem. Africans, compared with the white or Indian group, are also significantly less likely to see a pregnancy in the near future as a big problem. Boys from wealthier households are less likely to indicate that it would be a problem, probably reflecting access to resources sufficient to provide for a child. Most community measures were not significant predictors of individual-level worries about the timing of a pregnancy for boys. The risk environment, however, as measured by adult perceptions, was significantly and positively associated with boys' stating that a pregnancy in the near future would be a big problem. The risk environment as measured by peers' perception, in contrast, did not appear to influence boys' preferences.

The results for girls are strikingly different. For them, age does not make a difference to preferences in pregnancy timing. Race does so, but in the opposite direction than for boys: African girls are more than three times more likely than white or Asian girls to say that a pregnancy in the near future would be a big problem. Relationship status is also a strong predictor of pregnancy preferences; girls who are not currently in a relationship are more likely to report that a pregnancy would be a problem. No other individual or household characteristic was significant. Community influences appear to be very important for girls, however. Those from communities where many adolescents are 
Table 2 Logistic regression model predicting the proportion of sexually active adolescents for whom a pregnancy would present a big problem, KwaZulu-Natal province, South Africa, 1999

\begin{tabular}{|c|c|c|}
\hline Variable & $\frac{\text { Males }}{\text { Odds ratio }}$ & $\frac{\text { Females }}{\text { Odds ratio }}$ \\
\hline \multicolumn{3}{|l|}{ Age group } \\
\hline $14-15(r)$ & 1.00 & 1.00 \\
\hline $16-19$ & 0.40 & 0.89 \\
\hline $20-22$ & $0.22^{* *}$ & 0.51 \\
\hline \multicolumn{3}{|l|}{ Race } \\
\hline Other (r) & 1.00 & 1.00 \\
\hline African & $0.26^{*}$ & $3.08^{* * *}$ \\
\hline \multicolumn{3}{|l|}{ Relationship status } \\
\hline Steady relationship (r) & 1.00 & 1.00 \\
\hline Single & 0.62 & $1.57^{* *}$ \\
\hline \multicolumn{3}{|l|}{ Knows someone who died of AIDS } \\
\hline No (r) & 1.00 & 1.00 \\
\hline Yes & 0.81 & 1.14 \\
\hline Household wealth index & $0.68^{*}$ & 1.37 \\
\hline \multicolumn{3}{|l|}{ Parents living in household } \\
\hline Both (r) & 1.00 & 1.00 \\
\hline Single & 0.72 & 1.41 \\
\hline Neither & 0.95 & 0.98 \\
\hline Number of household shocks & 1.13 & 0.95 \\
\hline \multicolumn{3}{|l|}{ Young people enrolled in school (percent) } \\
\hline$<51(\mathrm{r})$ & 1.00 & 1.00 \\
\hline $51-75$ & 0.47 & 1.00 \\
\hline $76-100$ & 0.37 & $3.38^{* * *}$ \\
\hline Working in community (percent) & 0.50 & 1.36 \\
\hline Perceive friends are at risk of acquiring HIV & 0.83 & $10.01^{* *}$ \\
\hline $\begin{array}{l}\text { Adults who think that young people are at risk of acquiring HIV } \\
\text { (continuous } 1=\text { low to } 3=\text { high) }\end{array}$ & $3.00^{* *}$ & 0.74 \\
\hline Sample size (weighted) & $(677)$ & $(720)$ \\
\hline Log likelihood & -348.359 & -322.409 \\
\hline Probability $>$ F & $<0.001$ & $<0.001$ \\
\hline Pseudo $\mathrm{R}^{2}$ & 0.106 & 0.115 \\
\hline
\end{tabular}

${ }^{*}$ Significant at $\mathrm{p}<0.05 ;{ }^{* *} \mathrm{p}<0.01 ;{ }^{* * *} \mathrm{p}<0.001$. (r) $=$ Reference category.

enrolled in school are significantly more likely to state that pregnancy would be a problem than are those from communities where school enrollment is low. The community- 
level measure of the HIV-risk environment based on the perception of peer behavior is also a statistically significant indicator of pregnancy-timing preference for girls. In communities where most peers perceive a high level of risk, girls are far more likely to feel that being pregnant in the near future would be a big problem.

\section{DISCUSSION}

Our research question seeks to determine whether South African adolescents' attitudes toward pregnancy are affected by their perception of their risk of acquiring HIV. Are adolescents more concerned about pregnancy, which means having unprotected sex, if they live in environments of high risk? What are the relative influences of factors such as opportunities for education and employment compared with the impact of the HIV pandemic?

To explore the relationship between fertility preferences and HIV risk we modeled the probability of adolescents' reporting that a pregnancy in the near future would be a problem, using several measures of the environment of HIV risk, including peer behavior and social norms as independent variables. We find that educational and employment opportunities continue to affect fertility preferences, but we also find some evidence of the impact of the HIV pandemic. Some significant differences exist in the results for girls and boys, possibly because of the different consequences they experience as a result of pregnancy, or because their perceptions of the consequences of HIV risk in general differ.

Adolescent boys who wish to delay a partner's pregnancy appear to be more concerned about how issues that affect their ability to support a child will affect their opportunities for schooling, job training, and personal development than they are about acquiring HIV. For example, boys younger than 20, who are more likely to be in school and less likely to be working than older boys, are more concerned about a pregnancy in the near future than are older adolescents who may have completed school, than those who are working, and than those who have the ability to support a child. Wealth is associated with a lower level of concern about pregnancy. White and Asian boys are also more likely than African boys to view a pregnancy in the near future as a big problem because these populations evince stronger social disapproval of early childbearing and typically experience higher opportunity costs of paternal responsibilities. 
The fertility preferences of young men are also significantly associated with one measure of the HIV risk environment—namely, the extent to which adults in their community think adolescents are at high risk of acquiring HIV. A higher perception of risk within the adult community is associated with boys' increased desire to avoid a pregnancy. Adults' perception that the young are at high risk of HIV infection may not only be an indicator of the extent to which risky behaviors are practiced but also may translate into social support to encourage adolescents to avoid unprotected sex and use condoms.

We would expect girls to be more concerned than boys about the costs of an immediate pregnancy, such as leaving school, postponing matriculation, or having increased financial responsibility. In fact, girls are concerned, particularly about the impact on their education, with the proportion of 14-22-year-olds in their community enrolled in school being significantly associated with wanting to delay pregnancy. The importance of support — material and emotional—can also be seen. Girls without a regular partner are more likely to perceive becoming pregnant as a problem than are those who have a current partner.

Girls, of course, bear the direct burden of an adolescent pregnancy, but they also face a greater number of fears about simultaneously acquiring HIV infection and becoming pregnant. In addition to the risk of transmitting HIV infection to their infant during pregnancy or delivery, they may worry that a pregnancy would have a significant impact on their own health if they are infected with HIV, or they may be concerned about testing positive for HIV during antenatal services so that their serostatus would put them at risk of rejection by their partner or family.

As predicted, young women's preferences for the timing of pregnancy are affected by the environment of risk of acquiring HIV infection. For example, their preferences are significantly associated with their peer groups' perception of risk-perhaps a proxy for their perception of their own risk. Young women who live in communities where a large proportion of adolescents thought their friends were at high risk of acquiring HIV were significantly more likely to perceive that becoming pregnant in the near future would be a big problem. Young women seem to be more sensitive to peer influences, whereas boys appear to be more sensitive to the influence of adults' attitudes in their community. 
African girls are more than three times as likely to say that becoming pregnant would be a big problem compared with white and Asian girls. This finding refutes the suggestion put forth in previous research that babies born to young black South African girls are generally welcomed into their families, and that the girls face few if any consequences (Preston-Whyte 1990; Caldwell and Caldwell 1993). Our results indicate that African girls, relative to other groups, are deeply concerned about becoming pregnant at an early age. Our findings suggest that the attitude of the African girls in our sample may be linked to the risks of HIV infection that they confront.

The absence of certain expected relationships in our model is also of interest. Contrary to the results of Macintyre et al. (2001), which found a significant relationship among adult men between knowing someone who has died of AIDS and behavioral change, we found that knowing someone who died of AIDS has no relationship with pregnancy-timing preferences. Whether this knowledge contributes to adolescents' assessment of their own risk is not clear; they may perceive themselves as invulnerable to the diseases of adults or of people with different lifestyles.

The analysis presented here is based on cross-sectional survey data and has several limitations. We do not account adequately for the significant sociocultural differences among ethnic groups, and we use a crude measure of education (enrollment rates) that does not reflect either educational achievement or whether schooling included a life-skills curriculum, a major HIV-prevention approach used in South African schools. Interpretation of the effects of the risk environment is almost certainly complicated by the fact that some portion of our sample may have been tested for HIV. The answers of that portion of the sample to questions about the desirability of pregnancy might reflect a different perception of the consequences of future actions, compared with those of adolescents who can only guess at their current status and their future risk of HIV infection. Most important, the data do not allow us to understand the causal mechanisms governing the relationship between perception of risk and fertility preference. We do not know, for example, whether girls who want to become pregnant convince themselves that they are at little or no risk for HIV, nor do we know whether young people want to have children especially at a time when they think they might soon acquire a fatal disease. 
Our analysis suggests that for some adolescents—and for girls more than boysthe danger of HIV infection is becoming part of their calculus of the desirability of becoming pregnant soon. Factors that have been identified in studies of adolescent childbearing conducted over the last 15 years continue to be important: the detrimental impact of a pregnancy on schooling and increased financial and other responsibilities that follow the birth of a child. HIV risk is now also a factor in current decisions about the desirability of an adolescent pregnancy. For both boys and girls, the unprotected sex required for conception puts them at risk of HIV transmission. For girls, the double threat of pregnancy and HIV infection carries additional risks of disease transmission to the infant and antenatal testing with possible disclosure of positive results and rejection.

In order to proceed safely with childbearing in the context of the AIDS pandemic or to bolster their resolve to avoid an early pregnancy, adolescents need a realistic assessment of their HIV risk. Adolescents can benefit from HIV counseling and testing services that assist them to learn their own and their partner's HIV status and to make informed choices about childbearing based on that knowledge. Equally important is the reduction of the stigma surrounding HIV infection and the expansion of adolescents' and adults' access to information and support. This analysis shows that the influences on childbearing decisions of young men and women in South Africa are specific to their environment and that programs designed to help them should consider the separate needs of boys and girls for information services and support.

\section{NOTES}

The authors acknowledge Julian May and Stavros E. Stavrou, coinvestigators for the "Transitions to Adulthood in the Context of AIDS in South Africa" study, and Cathrien Alons-Kehus, formerly with the Department of International Health and Development, Tulane University, for assistance with data management and initial analysis. The study was supported by the Rockefeller Foundation and the United States Agency for International Development through the Horizons Program, the FOCUS on Young Adults Project, and the MEASURE/Evaluation project. 
1 Studies conducted in the United States also found a lack of association between HIV serostatus and fertility control among populations at high risk of HIV infection: HIV serostatus, AIDS knowledge, and perceived risk of becoming infected were not associated with reproductive decisions (Kline et al. 1995; Ahluwalia et al. 1998; Smits et al. 1999), in part because women and men had poor knowledge of perinatal transmission and a strong desire to have children (Williams 1990; Weiss et al. 1993; Smits et al. 1999).

2 This procedure was used to avoid creating a list of households prior to survey work (Turner et al. 1996).

3 Most respondents who reported ever having sex were sexually active in the last year (88 percent of males and 85 percent of females); however, a much smaller proportion was sexually active in the month before the survey (54 percent of males and 53 percent of females). Some adolescents may be abstaining from sexual relations for an extended period as a deliberate strategy to avoid pregnancy, and a parallel analysis of adolescents who are not sexually active would be useful. The distribution of those who are not sexually active is skewed according to the dependent variable, however, with only 3 percent of females and 8 percent of males reporting that a pregnancy would not be a problem.

4 Research on HIV and AIDS in South Africa has focused primarily on black South Africans. In the design of this study, the experience of adolescents of all races is of interest. We have included African, white, and Asian population groups in this analysis, but we have dropped the much smaller group of coloreds $(\mathrm{N}=20)$.

5 Five of the 118 EAs selected were excluded because of insecurity in the area or because permission of local authorities to enter the area was not obtained. An additional three EAs were discarded later because of problems with the collection of individual data.

6 The two community-level measures of HIV risk are correlated, but the correlation coefficient is low $(0.32, \mathrm{p}<0.001)$. 


\section{REFERENCES}

Ahluwalia, I.B., R.F. DeVellis, and J.C. Thomas. 1998. "Reproductive decisions of women at risk for acquiring HIV infection." AIDS Education and Prevention 10(1): 9097.

AIDS Analysis Africa. 2001. “2000 South Africa sero-prevalence rates.” AIDS Analysis Africa 11(6): Apr/May.

Aka-Dago-Akribi, H., A. Desgrées du Loû, P. Msellati, R. Dossou, and C. WelffensEkra. 1999. "Issues surrounding reproductive choice for women living with HIV in Abidjan, Côte d'Ivoire." Reproductive Health Matters 7(13): 20-29.

Allen, S., J. Tice, P. Van de Perre, A. Serufilira, E. Hudes, F. Nsengumuremyi, J. Bogaerts, C. Lindan, and S. Hulley. 1992. "Effect of serotesting with counseling on condom use and seroconversion among HIV-discordant couples in Africa." British Medical Journal 304(6842): 1605-1609.

Allen, S., A. Serufilira, V. Gruber, S. Kegeles, P. Van de Perre, M. Carael, and T.J. Coates. 1993. "Pregnancy and contraceptive use among urban Rwandan women after HIV testing and counseling." American Journal of Public Health 83(5): 705-710.

Ankrah, M.E. 1991. "AIDS and the social side of health." Social Science \& Medicine 32(9): 967-980.

Brown, Lisanne, Kate Macintyre, Stavros Stavrou, Cathrien Kehus, Ali Karim, and A. Robinson. 2001. "Measuring community effects on adolescent reproductive health in Kwa-Zulu Natal, South Africa." Paper presented at the annual meeting of the Population Association of America, Washington, DC, 29-31 March.

Caldwell, John C. and Pat Caldwell. 1993. "The South African fertility decline." Population and Development Review 19(2): 225-262.

Carpenter, L.M., J.S. Nakiyingi, A. Ruberantwari, S.S. Malamba, A. Kamali, and J.A.G. Whitworth. 1997. "Estimates of the impact of HIV infection on fertility in a rural Ugandan population cohort." Health Transition Review 7(supplement 2): 113-126.

Community Agency for Social Enquiry (CASE). 1995. Let the Sky be the Limit. Soul City I Evaluation Report. Cape Town: CASE. 
Central Statistical Service. 1997. Census '96: Preliminary Estimates of the Size of the Population of South Africa. Pretoria: Central Statistics.

Desgrées du Loû, Annabel, Philippe Msellati, A. Yao, V. Noba, Ida Viho, R. Ramon, Christiane Welffens-Ekra, and F. Dabis. 1999. "Impaired fertility in HIV-1 infected pregnant women: A clinic based survey in Abidjan, Côte d'Ivoire.” AIDS 13(4): 517-521.

Duncan, G. and S. Raudenbush. 1999. "Assessing the effects of context in studies of child and youth development." Educational Psychologist 34(1): 29-41.

Family Health International/AIDSCAP. 1996. AIDS in Kenya: Socioeconomic Impact and Policy Implications. Arlington, VA: FHI/AIDSCAP.

Gage, Anastasia. 1998. "Sexual activity and contraceptive use: The components of the decisionmaking process." Studies in Family Planning 29(2): 154-166.

Glynn, J.R., A. Buve, M. Carael, M. Kahindo, I.B. Macauley, R.M. Musonda, E. Jungmann, F. Tembo, and L. Zekeng. 2000. "Decreased fertility among HIV-1infected women attending antenatal clinics in three African cities." Journal of Acquired Immune Deficiency Syndromes 25(4): 345-352.

Gray, R.H., M.J. Wawer, D. Serwadda, N. Sewankambo, C. Li, F. Wabwire-Mangen, L. Paxton, N. Kiwanuka, G. Kigozi, J. Konde-Lule, T.C. Quinn, C.A. Gaydos, and D. McNairn. 1998. "A population-based study of fertility in women with HIV-1 infection in Uganda." Lancet 351(9096): 98-103.

Gready, Meg, Barbara Klugman, Emelda Boikanyo, Helen Rees, and Makhosazana Xaba. 1997. "South African women's experiences of contraception and contraceptive services." In Beyond Acceptability: Users' Perspectives on Contraception. London: Reproductive Health Matters for the World Health Organization. Pp. 23-35.

Gregson, Simon, Tom Zhuwau, Roy M. Anderson, and Stephen K. Chandiwana. 1997. "HIV and fertility change in rural Zimbabwe." Health Transition Review 7(supplement 2): 89-112.

Hermalin, Albert I. 1983. "Fertility regulation and its costs: A critical essay." In Rodolfo A. Bulatao and Ronald D. Lee (eds.), Determinants of Fertility in Developing Countries. New York: Academic Press. Pp. 1-53. 
Jackson, Elizabeth and Abigail Harrison. 1999. "Sexual myths around HIV/STDs and sexuality: The gap between awareness and understanding among rural South African youth." Unpublished.

Jewkes, Rachel, Loveday Penn-Kekana, Jonathan Levin, Matsie Ratsaka, and Margaret Schrieber. 1999. 'He must give me money, he mustn't beat me' : Violence Against Women in Three South African Provinces. Pretoria: CERSA (Women's Health), South African Medical Research Council.

Kamenga, M., R.W. Ryder, M. Jingu, N. Mbuyi, L. Mbu, F. Behets, C. Brown, and W.L. Heyward. 1991. "Evidence of marked sexual behavior change associated with low HIV-1 seroconversion in 149 married couples with discordant HIV-1 serostatus: Experience at an HIV counseling center in Zaire." AIDS 5(1): 61-67.

Kaufman, Carol, Thea de Wet, and Jonathan Stadler. 2001. "Adolescent pregnancy and parenthood in South Africa." Studies in Family Planning 32(2): 147-160.

Kelly, Kevin. 2000. Communicating for Action: A Contextual Evaluation of Youth Response to HIVIAIDS. Sentinel Site Monitoring and Evaluation Project, Stage One Report, Beyond Awareness Campaign. Pretoria: HIV/AIDS and STD Directorate, South Africa Department of Health.

Keogh, P., S. Allen, C. Almedal, and B. Temahagili. 1994. "The social impact of HIV infection on women in Kigali, Rwanda: A prospective study." Social Science \& Medicine 38(8): 1047-1053.

Kigadye, R.M., A. Klokke, A. Nicoll, K.M. Nyamuryekung'e, M. Borgdorff, L. Barongo, U. Laukamm-Josten, F. Lisekie, H. Grosskurth, and F. Kigadye. 1993. "Sentinel surveillance for HIV-1 among pregnant women in a developing country: 3 years' experience and comparison with a population serosurvey." AIDS 9(6): 452-456.

King, R., J. Estey, S. Allen, S. Kegeles, W. Wolf, C. Valentine, and A. Serufilira. 1995. "A family planning intervention to reduce vertical transmission of HIV in Rwanda." AIDS 9(supplement 1): S45-S51.

Kirby, D. 2001. Emerging Answers: Research Findings on Programs to Reduce Teen Pregnancy. Washington, DC: National Campaign to Prevent Teen Pregnancy. 
Kline, A., J. Strickler, and J. Kempf. 1995. "Factors associated with pregnancy and pregnancy resolution in HIV seropositive women." Social Science \& Medicine 40(11): 1539-1547.

Lear, Dana. 1995. "Sexual communication in the age of AIDS: The construction of risk and trust among young adults." Social Science \& Medicine 41(9): 1311-1323.

LeClerc-Madlala, S. 1997. "Infect one, infect all: Zulu youth response to the AIDS epidemic in South Africa." Medical Anthropology 17(4): 363-380.

Lurie, Mark, Abigail Harrison, David Wilkinson, and Salim Abdool-Karim. 1997. "Circular migration and sexual networking in rural Kwa Zulu/Natal: Implications for the spread of HIV and other sexually transmitted diseases." Health Transition Review 7(supplement 3): 17-27.

Maman, S., J. Mbwambo, M. Sweat, N. Hogan, and G.P. Kilonzo. 1999. "Intersections of HIV and violence: Implications for HIV counseling and testing in Dar es Salaam, Tanzania." Paper presented at a roundtable discussion at the Eleventh International Conference on AIDS and STDs in Africa, Lusaka, Zambia, 12-16 September.

Macintyre, Kate, Lisanne Brown, and S. Sosler. 2001. " 'It is not what you know but who you knew': Relating behavior change to AIDS mortality in Africa." AIDS Prevention and Education 13(1): 160-174.

MacPhail, Catherine and Catherine Campbell. 2001. " 'I think condoms are good but, aai, I hate those things': Condom use among adolescents and young people in a South African township." Social Science \& Medicine 52(11): 1613-1627.

Meursing, Karla and Flora Sibindi. 1995. "Condoms, family planning and living with HIV in Zimbabwe." Reproductive Health Matters 5(May): 56-67.

National Progressive Primary Health Care Network (NPPHCN). 1995. Youth Speak Out for a Healthy Future. Cape Town: NPPHCN/UNICEF.

Preston-Whyte, Eleanor. 1990. "Qualitative perspectives on fertility trends among African teenagers." In W.P. Mostert and J.M. Lotter (eds.), South Africa's Demographic Future. Pretoria: Human Sciences Research Council. 
. 1994. "Gender and the lost generation: The dynamics of HIV transmission among black South African teenagers in Kwa Zulu-Natal." Health Transition Review 4 (supplement): 241-255.

. 1999. "Reproductive health and the condom dilemma in South Africa." In John C. Caldwell et al. (eds.), Resistances to Behavioural Change to Reduce HIV/ AIDS in Predominantly Heterosexual Epidemics in Third World Countries. Canberra: Health Transition Centre, National Center for Epidemiology and Population Health, Australian National University.

Preston-Whyte, Eleanor and M. Zondi. 1992. "African teenage pregnancy: Whose problem?” In S. Burman and Eleanor Preston-Whyte (eds.), Questionable Issue: Illegitimacy in South Africa. Cape Town: Oxford University Press.

Ramphele, Mampele. 1997. "Adolescents and violence: 'Adults are cruel, they just beat, beat, beat." "Social Science \& Medicine 45(8): 1189-1197.

Richter, Linda. 1996. A Survey of Reproductive Health Issues among Urban Black Youth in South Africa. Pretoria: Society for Family Health.

Ross, A., D. Morgan, R. Lubega, L.M. Carpenter, B. Mayanja, and J.A.G. Whitworth. 1999. "Reduced fertility associated with HIV: The contribution of pre-existing subfertility." AIDS 13(15): 2133-2141.

Rutenberg, Naomi, Ann E. Biddlecom, and Frederick A.D. Kaona. 2000. "Reproductive decision-making in the context of HIV and AIDS: A qualitative study in Ndola, Zambia." International Family Planning Perspectives 26(3): 124-130.

Rutenberg, Naomi, Cathrien Kehus-Alons, Lisanne Brown, Kate Macintyre, A. Dallimore, and Carol Kaufman. 2001. Transitions to Adulthood in the Context of AIDS in South Africa: Report of Wave I. Washington, DC: Horizons Program.

Ryder, R.W., V.L. Batter, M. Nsuami, N. Badi, L. Mundele, B. Matela, M.Utshudi, and W.L. Heyward. 1991. "Fertility rates in 238 HIV-1-seropositive women in Zaire followed for 3 years post-partum." AIDS 5(12): 1521-1527.

Setel, Philip. 1995. "The effects of HIV and AIDS on fertility in East and Central Africa." Health Transition Review 5(supplement): 179-189. 
Sewankambo, N.K., M.J. Wawer, R.H. Gray, D. Serwadda, C. Li, R.Y. Stallings, S.D. Musgrave, and J. Konde-Lule. 1994. "Demographic impact of HIV infection in rural Rakai District in Uganda: Results of a population-based cohort study." AIDS 8(12): 1707-1713.

Singh, Susheela. 1998. "Adolescent childbearing in developing countries: A global review." Studies in Family Planning 29(2): 117-136.

Smits, A.K., C.A. Georgen, J.A. Delaney, C. Williamson, L.M. Mundy, and V.J. Fraser. 1999. "Contraceptive use and pregnancy decisionmaking among women with HIV." AIDS Patient Care and STDS 13(12): 379-746.

South Africa Department of Health (SADOH), Medical Research Council, and Macro International (MI). 1999. South Africa Demographic and Health Survey 1998, Preliminary Report. Pretoria: SADOH and MI.

Temmerman, M., S. Moses, D. Kiragu, S. Fusallah, I.A. Wamola, and P. Piot. 1990. "Impact of single session post-partum counseling of HIV infected women on their subsequent reproductive behavior." AIDS Care 2(3): 247-252.

Turner, A.G., R.G. Magnani, and M. Shuaib. 1996. “A not quite as quick but much cleaner alternative to the expanded programme on immunization (EPI) cluster survey design.” International Journal of Epidemiology 25(1): 198-203.

Ulin, Priscilla R. 1992. "African women and AIDS: Negotiating behavioral change." Social Science \& Medicine 34(1): 63-73.

U.S. Census Bureau. 1999. HIVIAIDS Surveillance Data Base. Washington, DC: Population Division, International Programs Center.

Varga, Christine, A. 1997. "Sexual decision-making and negotiation in the midst of AIDS: Youth in KwaZulu-Natal, South Africa." Health Transition Review 7(supplement 3): 45-67.

. 1999. "South African young people's sexual dynamics: Implications for behavioural responses to HIV/AIDS.” In John C. Caldwell et al. (eds.), Resistances to Behavioural Change to Reduce HIVIAIDS in Predominantly Heterosexual Epidemics in Third World Countries. Canberra: Health Transition Centre, 
National Center for Epidemiology and Population Health, Australian National University.

Varga, Christine, A. and L. Makubalo. 1996. "Sexual (non) negotiation.” Agenda 28: 31-38.

Weiss, S.H., C.B. Weston, and J. Quirinale. 1993. "Safe sex? Misconceptions, gender differences and barriers among injection drug users: A focus group approach." AIDS Education and Prevention 5(4): 279-293.

Whiteside, A. 1999. "SA’s 1998 survey results show no let-up." AIDS Analysis Africa 10(1).

Williams, A.B. 1990. "Reproductive concerns of women at risk for HIV infection." Journal of Nurse-Midwifery 35(5): 292-298.

Wood, Katharine and Rachel Jewkes. 1997. "Violence, rape, and sexual coercion: Everyday love in a South African township." Gender and Development 5(2): 4146.

Wood, Katharine, Joyce Maepa, and Rachel Jewkes. 1998. "Adolescent sex and contraceptive experiences: Perspectives of teenagers and clinic nurses in the Northern Province." Unpublished. 


\title{
POLICY RESEARCH DIVISION WORKING PAPERS
}

\author{
Recent Back Issues
}

133 Mary Arends-Kuenning and Sajeda Amin, "The effects of schooling incentive programs on household resource allocation in Bangladesh."

134 John Bongaarts and Charles F. Westoff, "The potential role of contraception in reducing abortion."

135 John B. Casterline and Steven W. Sinding, "Unmet need for family planning in developing countries and implications for population policy."

*136 Carol E. Kaufman, Thea de Wet, and Jonathan Stadler, "Adolescent pregnancy and parenthood in South Africa."

*137 Valerie L. Durrant and Zeba A. Sathar, "Greater investments in children through women's empowerment: A key to demographic change in Pakistan?"

138 Sajeda Amin, Alaka Malwade Basu, and Rob Stephenson, "Spatial variation in contraceptive use in Bangladesh: Looking beyond the borders."
139 Geoffrey McNicoll, "Managing population-environment systems: Problems of institutional design."

140 Barbara S. Mensch, Barbara L. Ibrahim, Susan M. Lee, and Omaima ElGibaly, "Socialization to gender roles and marriage among Egyptian adolescents."

141 John Bongaarts and Elof Johansson, "Future trends in contraception in the developing world: Prevalence and method mix."

*142 Alaka Malwade Basu and Sajeda Amin, "Some preconditions for fertility decline in Bengal: History, language identity, and an openness to innovations."

143 Zeba Sathar, Cynthia B. Lloyd, Cem Mete, and Minhaj ul Haque, "Schooling opportunities for girls as a stimulus for fertility change in rural $\mathrm{Pa}-$ kistan."

\footnotetext{
* No longer available
} 
144 John Bongaarts, "Household size and composition in the developing world."

145 John B. Casterline, Zeba A. Sathar, and Minhaj ul Haque, "Obstacles to contraceptive use in Pakistan: A study in Punjab."

146 Zachary Zimmer, Albert I. Hermalin, and Hui-Sheng Lin, "Whose education counts? The impact of grown children's education on the physical functioning of their parents in Taiwan."

147 Philomena Nyarko, Brian Pence, and Cornelius Debpuur, "Immunization status and child survival in rural Ghana."

*148 John Bongaarts and Zachary Zimmer, "Living arrangements of older adults in the developing world: An analysis of DHS household surveys."

149 Markos Ezra, "Ecological degradation, rural poverty, and migration in Ethiopia: A contextual analysis."
150 Cynthia B. Lloyd, Sahar El Tawila, Wesley H. Clark, and Barbara S. Mensch, "Determinants of educational attainment among adolescents in Egypt: Does school quality make a difference?"

151 Barbara S. Mensch, Paul C. Hewett, and Annabel Erulkar, "The reporting of sensitive behavior among adolescents: A methodological experiment in Kenya."

152 John Bongaarts, "The end of the fertility transition in the developed world."

153 Mark R. Montgomery, GebreEgziabher Kiros, Dominic Agyeman, John B. Casterline, Peter Aglobitse, and Paul Hewett, "Social networks and contraceptive dynamics in southern Ghana."

*154 Paul C. Hewett and Mark R. Montgomery, "Poverty and public services in developing-country cities."

* No longer available 
155 Zachary Zimmer, Linda G. Martin, and Ming-Cheng Chang, "Changes in functional limitations and survival among the elderly in Taiwan: 1993, 1996, and 1999."

156 John Bongaarts and Griffith Feeney, "How long do we live?"

157 Zachary Zimmer and Sovan Kiry Kim, "Living arrangements and socio-demographic conditions of older adults in Cambodia."

158 Geoffrey McNicoll, "Demographic factors in East Asian regional integration."

159 Carol E. Kaufman, Shelley Clark, Ntsiki Manzini, and Julian May, "How community structures of time and opportunity shape adolescent sexual behavior in South Africa."
160 Julia Dayton and Martha Ainsworth, "The elderly and AIDS: Coping strategies and health consequences in rural Tanzania."

161 John Bongaarts, "The end of the fertility transition in the developing world."

162 Naomi Rutenberg, Carol E. Kaufman, Kate Macintyre, Lisanne Brown, and Ali Karim, "Pregnant or positive: Adolescent childbearing and HIV risk in South Africa." 